\title{
Caveolin and $\beta_{1}$-integrin Coordinate Angiotensinogen Expression in Cardiac Myocytes
}

\author{
Hind Lal, Ph.D. ${ }^{4}$, Suresh K. Verma, Ph.D. ${ }^{5}$, Hao Feng, Ph.D. ${ }^{2}$, Honey B. Golden, Ph.D. ${ }^{2}$, Fnu \\ Gerilechaogetu, Ph.D. ${ }^{2}$, Damir Nizamutdinov, M.D./Ph.D. ${ }^{2}$, Donald M. Foster, Ph.D. ${ }^{1}$, \\ Shannon S. Glaser, Ph.D. ${ }^{1,3}$, and David E. Dostal, Ph.D. ${ }^{1,3}{ }^{*}$ \\ ${ }^{1}$ Central Texas Veterans Health Care System, Texas A\&M Health Science Center, 1901 South \\ 1st Street, Temple, Texas 76504 \\ ${ }^{2}$ Division of Molecular Cardiology, Cardiovascular Research Institute, Texas A\&M Health Science \\ Center, 1901 South 1st Street, Temple, Texas 76504
}

${ }^{3}$ Division of Gastroenterology, College of Medicine, Texas A\&M Health Science Center, 1901 South 1st Street, Temple, Texas 76504

${ }^{4}$ Center for Translational Medicine, Thomas Jefferson University, Philadelphia, PA, USA

${ }^{5}$ Feinberg Cardiovascular Research Institute, Northwestern University, Chicago, IL, USA

\section{Abstract}

Background-The cardiac renin-angiotensin system (RAS) has been implicated in mediating myocyte hypertrophy and remodeling, although the biochemical mechanisms responsible for regulating the local RAS are poorly understood. Caveolin-1 (Cav-1)/Cav-3 double-knockout mice display cardiac hypertrophy, and in vitro disruption of lipid rafts/caveolae using methyl- $\beta$ cyclodextrin (M $\beta C D)$ abolishes cardiac protection.

Methods-In this study, neonatal rat ventricular myocytes (NRVM) were used to determine whether lipid rafts/caveolae may be involved in the regulation of angiotensinogen (Ao) gene expression, a substrate of the RAS system.

Results-Treatment with $\mathrm{M} \beta C D$ caused a time-dependent upregulation of Ao gene expression, which was associated with differential regulation of mitogen-activated protein (MAP) kinases ERK1/2, p38 and JNK phosphorylation. JNK was highly phosphorylated shortly after MBCD treatment $(2-30 \mathrm{~min})$, whereas marked activation of ERK1/2 and p38 occurred much later $(2-4$ h). $\beta_{1 D}$-integrin was required for M $B C D$-induced activation of the MAP kinases. Pharmacologic inhibition of ERK1/2 and JNK enhanced MBCD-induced Ao gene expression, whereas p38 blockade inhibited this response. Adenovirus-mediated expression of wild-type p38a enhanced $\mathrm{M} \beta \mathrm{CD}$-induced Ao gene expression; conversely expression of dominant negative p38a blocked the stimulatory effects of MBCD. Expression of Cav-3 siRNA stimulated Ao gene expression, whereas overexpression of Cav-3 was inhibitory. Cav-1 and Cav-3 expression levels were found to be positively regulated by $\mathrm{p} 38$, but unaffected by ERK1/2 and JNK.

(C) 2012 Elsevier Ireland Ltd. All rights reserved.

*Correspondence: David E. Dostal, PhD, Division of Molecular Cardiology, 1901 South 1st Street, Bldg. 205, Temple TX 76504, Tel: 254-743-2464, Fax: 254-743-0165, ddostal@medicine.tamhsc.edu.

Publisher's Disclaimer: This is a PDF file of an unedited manuscript that has been accepted for publication. As a service to our customers we are providing this early version of the manuscript. The manuscript will undergo copyediting, typesetting, and review of the resulting proof before it is published in its final citable form. Please note that during the production process errors may be discovered which could affect the content, and all legal disclaimers that apply to the journal pertain. 
Conclusion-Collectively, these studies indicate that lipid rafts/caveolae couple to Ao gene expression through a mechanism that involves $\beta_{1}$-integrin and the differential actions of MAP kinase family members.

\section{Keywords}

Caveolae; Angiotensinogen; MAP kinases; Cardiac myocytes

\section{Introduction}

The renin-angiotensin-system (RAS) plays a key role in mediating ventricular hypertrophy and remodeling $[1,2]$. Treatment with angiotensin converting enzyme (ACE) inhibitors or angiotensin II (Ang II) type-I receptor $\left(\mathrm{AT}_{1}\right)$ blockers significantly improve cardiac function, as well as reverse ventricular remodeling and reduce morbidity and mortality in patients with heart failure [3]. Angiotensinogen (Ao), a substrate of the RAS system, has been implicated in the pathogenesis of hypertension and congestive heart failure.

Angiotensin II, the most biologically active peptide of the RAS, affects several aspects of cardiac function including contractility, cell metabolism, cellular growth, differentiation, apoptosis and gene expression [4]. Progression of heart failure is associated with a steady increase of Ang II formation by the myocardium, regardless of the underlying etiology [1, $2]$. We have recently reported that $\beta_{1}$-integrin reciprocally regulates mechanical stretchinduced MAP kinase activation [5], and stress activated kinases p38 and JNK play important roles in mechanical stretch-induced regulation of Ao gene expression [6]. However, the specific components coupling $\beta_{1}$ integrin to $\mathrm{p} 38$ and JNK activation remain to be determined.

Lipid rafts, plasma membrane domains formed through the association of sphingolipid and cholesterol, have become recognized as essential for many types of cellular signal transduction processes. Caveolins, $22-24 \mathrm{kDa}$ scaffolding proteins which associate with lipid rafts to form caveolae, have been shown to be important structural elements involved in myocyte signal-transduction [7]. Three caveolin isoforms, Cav-1, Cav-2 and Cav-3 have been identified. Cav-1 and Cav-2 are expressed in most cell types, whereas Cav- 3 is primarily expressed in striated muscle [8]. In addition to concentrating signal transducers within a distinct region of the plasma membrane $[9,10]$, caveolins functionally regulate the activation states of several caveolae-associated signaling molecules by sequestering them in an inactive state [11]. Caveolae have also been shown to be required for $\beta_{1}$-integrinmediated signaling [12], indicating that a functional link exists between $\beta_{1}$-integrins and caveolae. Stretch-induced translocation of caveolin from caveolae to non-caveolar membrane sites has been shown to be critical for coupling integrin signaling to ERK activation in vascular smooth muscle cells [13]. Additionally, caveolae and caveolins have been implicated in the wide range of cardiac protection [14]. It has been suggested that caveolin in caveolae may sequester ERK and prevent its activation, but translocation of caveolin to noncaveolar sites, in response to stretch, induces caveolin-mediated ERK activation through an association with $\beta_{1}$-integrin [13]. Although caveolae and caveolins are important for regulating $\beta_{1}$-integrin-mediated ERK activation, much less is known regarding the importance of caveolins in coupling $\beta_{1}$-integrin to p38 and JNK activation. In this study, we tested the hypothesis that caveolae, together with $\beta_{1}$ integrin and MAP kinases, modulate Ao gene expression in neonatal rat cardiac myocytes. 


\section{Materials and methods}

\subsection{Antibodies and reagents}

Phospho-ERK-p44/42-Thr ${ }^{202} / \mathrm{Tyr}^{204}$ antibody (9101), ERK polyclonal antibody (9102), phospho-p38-Thr ${ }^{180} / \mathrm{Tyr}^{182}$ antibody (9211), p38 antibody (5F11), phospho-SAPK/JNK$\mathrm{Thr}^{183} / \mathrm{Tyr}^{185}$ antibody (9251), JNK antibody (9252) and horseradish peroxidase-conjugated secondary antibodies were obtained from Cell Signaling Technology, Inc. (Danvers, MA). Glyceraldehyde-3-phosphate dehydrogenase (GAPDH) antibody (MAB1501) was obtained from Santa Cruz Biotechnology, Inc. (Santa Cruz, CA). Bovine serum albumin (BSA, diagnostic grade K) was obtained from Celluliance (Kanakee, IL). Enhanced chemiluminescence (ECL) reagent (Western Lightning ${ }^{\mathrm{TM}}$ ) was obtained from Perkin Elmer Life Science (Boston, MA). MBCD, U0126, SB202190 and SP600125 were purchased from Calbiochem (San Diego, CA).

\subsection{Isolation of neonatal rat ventricular myocytes}

Primary cultures of NRVMs were prepared from 1 to 2-day-old Sprague Dawley rats as previously described [5]. Dispersed cardiac cells were separated using a discontinuous Percoll gradient, containing a density of $1.060 \mathrm{gm} / \mathrm{L}$ (nonmyocyte layer) and $1.086 \mathrm{gm} / \mathrm{L}$ (myocyte layer). NRVM were plated on Bioflex plates (Flexcell International Corporation, Hillsborough, NC), coated with collagen-IV $\left[1 \mu \mathrm{g} / \mathrm{cm}^{2}\right]$ ), at a density of $0.75 \times 10^{6}$ cells/ well in DMEM/M199 medium and maintained at $37^{\circ} \mathrm{C}$ in humid air with $5 \% \mathrm{CO}_{2}$. Cytosine arabinoside $(100 \mu \mathrm{M})$ was added to prevent cell division of nonmyocytes and culture media was changed to serum-free $24 \mathrm{~h}$ prior to initiation of experiments. NRVM were $>95 \%$ pure, as revealed by microscopic observation of contractile characteristics and by flow cytometry, after staining with anti-desmin antibody (Sigma Chemical Co., St. Louis, MO). This study conforms to the Guide for the Care and Use of Laboratory Animals published by the US National Institutes of Health (NIH Publication No. 85-23, revised 1996). Experimental protocols were approved by the Institutional Animal Care and Use Committee of Texas A\&M Health Science Center.

\subsection{Adenovirus expansion and infection of cells}

Recombinant adenoviruses expressing Tac- $\beta_{1 \mathrm{D}}$ and $l a c Z$ were gifts from Robert Ross (University of San Diego, San Diego, CA), whereas wild-type p38a (Ad-p38a-WT), and p38a dominant-negative (Ad-p38a-DN) were gifts from Dr. Yibin Wang (University of California, Los Angeles). Amplification of adenovirus was performed in transformed 293 human embryonic kidney (HEK) cells (CRL-1573, ATCC, Manassas, VA), followed by purification on $\mathrm{CsCl}$ gradients. Viral MOIs were determined by dilution assay in transformed 293 human embryonic kidney (HEK) cells CRL-1573 (American Type Culture Collection, Manassas, VA) cultured in 6-well clusters, as advised by the supplier. Titration assays were used to determine the lowest MOI which would results a significant increase in expressed protein and/or block endogenous target protein phosphorylation in NRVM. After $24 \mathrm{~h}$ of plating, NRVM were infected with following concentrations of adenovirus diluted in DMEM/medium 199: Tac- $\beta_{1}$ (50 MOI), Ad-p38a-WT (50 MOI), or Ad-p38a-DN (100 MOI). Corresponding MOI of adenovirus expressing lacZ/green fluorescent protein (GFP) were used to control for viral effects. After $24 \mathrm{~h}$ of transfection, the medium was replaced with virus-free DMEM/medium 199, and cells were cultured for an additional $12 \mathrm{~h}$ prior to experiments. At optimized virus concentrations, there were no obvious signs of cell toxicity (cell detachment, formation of intracellular vacuoles, cell rounding). 


\subsection{Lipid raft/caveolae disruption using $M \beta C D$}

NRVM were incubated for various times at $37^{\circ} \mathrm{C}$ in serum-free media without (control) or serum-free medium with $5 \mathrm{mM} \mathrm{M \beta CD}$. M $\beta C D$ is a chemical that does not enter cells, but disassembles lipid rafts and caveolae by depleting cholesterol from the plasma membrane. This technique has been validated in several cell types, including cardiac myocytes $[15,16]$.

\subsection{SiRNA preparation and transfection}

In order to selectively "knock down" the expression of Cav-3 in NRVM, we designed a siRNA duplex targeted to the rat Cav-3 (Gene ID: NM_019155.2), sequence sense 5'GGGCACUUACAGCUUCGAU-3 and antisense 5AUCGAAGCUGUAAGUGCCC-3,starting at 282 from the open reading frame (136-591) of rat Cav-3 mRNA, by using Invitrogen BLOCK-iT RNAi Designer software. The RNA sequence used as a negative control for siRNA activity was: 5GGGATTCCGACCTTACGAT-3 designed by BLOCK-iT ${ }^{\mathrm{TM}}$ RNAi Designer software. Small interfering RNA duplex oligonucleotides were purchased from Invitrogen. In preliminary experiments, we optimized conditions for the efficient transfection of NRVM using siRNA. Fresh medium was added $6 \mathrm{~h}$ post-transfection, and experiments were conducted $48 \mathrm{~h}$ after transfection. To assess the specific effect of Cav-3 siRNA on silencing Cav-3 expression, the protein levels of Cav-3 were detected by immunoblot analysis $48 \mathrm{~h}$ post-transfection. We found that optimal conditions for siRNA knockdown involved transfecting cardiac myocytes with siRNA $(150 \mathrm{nM})$ and Lipofectamine $2000(0.15 \% \mathrm{v} / \mathrm{v})$, following protocols provided by the manufacturer (Invitrogen Life Science, Carlsbad, CA).

\subsection{Immunofluorescent staining}

Indirect Immunofluorescence staining was performed on cardiac cells cultured on Lab-Tek ${ }^{\mathrm{R}}$ chamber slides $^{\mathrm{TM}}$ (Nalge Nunc International, Rochester, NY) coated with collagen IV. Briefly, cells were washed with PBS and fixed with 4\% paraformaldehyde for 20 minutes at $22^{\circ} \mathrm{C}$. Following three extensive washings with PBS, cells were permeabilized with $0.05 \%$ Triton-X 100 and blocked with 5\% bovine serum albumin in PBS buffer for $30 \mathrm{~min}$ at 22 ${ }^{\circ} \mathrm{C}$. Cells were then incubated with the specific primary antibodies for Cav-1 (1:150, Sc-894 rabbit polyclonal antibody, Santa Cruz Biotechnology), Cav-3 (1:150, BD Transduction Laboratories) and/or mouse desmin (1:200, mouse monoclonal antibody [IgG $2 \mathrm{~b}], \mathrm{RD} 301$, Abcam) for $1 \mathrm{~h}$ at $37^{\circ} \mathrm{C}$. Cells were co-stained for $45 \mathrm{~min}$ at $37^{\circ} \mathrm{C}$ with Alexa-Fluor ${ }^{\mathrm{R}}-488$ labeled chicken anti-rabbit (1:150), Alexa Fluor ${ }^{R_{-}} 594$ labeled goat anti-mouse (1:150) antibodies, goat anti-mouse Alexa-Fluor ${ }^{\mathrm{R}}-594 \operatorname{IgG}_{2 b}(1: 150)$. The nucleus was stained with 4',6-diamidino-2-phenylindole, dihydrochloride (DAPI). Stained cells were mounted with Prolong Gold ${ }^{\mathrm{R}}$ antifade mounting medium (Invitrogen Corporation, Carlsbad, CA, USA) and viewed with a FluoView ${ }^{\mathrm{TM}}$ FV1000 Olympus epifluorescence microscope (model IX81).

\subsection{Lipid rafts/caveolae labeling}

Lipid rafts/caveolae were stained in cardiac cells cultured on collagen IV coated Lab-Tek ${ }^{\circledR}$ II chamber slides (Thermo Scientific, Rochester, NY). After treatment with M $\beta C D$ (5 mM) and cholesterol $(1 \mathrm{mM})$, cells were incubated in the presence of $1 \mu \mathrm{g} / \mathrm{ml}$ of cholera toxin subunit B (CT-B) (Invitrogen Corporation, Carlsbad, CA) for 10 minutes at $4^{\circ} \mathrm{C}$. Cells were gently washed with chilled PBS and incubated with rabbit anti-CT-B antibody (Invitrogen Corporation, Carlsbad, CA) for 15 minutes at $4^{\circ} \mathrm{C}$ to crosslink the CT-B-labeled lipid rafts. Cells were then fixed, permeabilized, immunostained with Alexa $488^{\mathrm{R}_{\text {-conjugated }}}$ secondary antibody and visualized as described in section 2.6. 


\subsection{Preparation of cell lysates and Western blotting}

Cell lysates were obtained by lifting NRVM cultured on 6-well pates using lysis buffer (Cell Signaling) containing $10 \mu \mathrm{g} / \mathrm{ml}$ aprotinin, $10 \mu \mathrm{g} / \mathrm{ml}$ leupeptin, $1 \mathrm{mM}$ 2-(2-aminoethyl)benzenesulfonyl fluoride, hydrochloride and $1 \mathrm{mM}$ sodium orthovanadate. Insoluble material was removed by centrifugation for $15 \mathrm{~min}$ at $14,000 \mathrm{~g}$ and samples were boiled with loading buffer and protein was determined using a kit (Bio-Rad DC Protein Assay) according to the manufacturer's recommendation (Bio-Rad, Hercules, CA). Western blot analysis was performed as previously described [5]. Briefly, equal amounts of protein (30 $\mu \mathrm{g}$ ) from cell lysates were separated by SDS-PAGE and blotted onto polyvinylidene fluoride (PVDF) transfer membranes. The membranes were blocked for $2 \mathrm{~h}$ using 5\% BSA in TBST buffer (10 mM Tris, $100 \mathrm{mM} \mathrm{NaCl}, 0.1 \%$ Tween 20, pH 7.4). Blots were incubated with the primary antibodies in 5\% BSA in TBST buffer overnight at $4^{\circ} \mathrm{C}$ with light agitation. Bound primary antibodies were visualized using horseradish peroxidase-labeled secondary antibodies and detected using ECL. Densities of the protein bands were measured using ImageQuant software. Signals from the phosphoproteins were normalized to total protein, obtained by stripping and reprobing blots with the corresponding total antibody. Blots were again stripped and probed with glyceraldehyde-3-phosphate dehydrogenase (GAPDH) antibody to confirm equal loading.

\subsection{Quantitative measurement of Ao mRNA using real-time RT-PCR}

A commercial kit (Totally RNA ${ }^{\mathrm{TM}}$, Ambion, Austin, TX) was used to isolate RNA from NRVM. First strand cDNA was reverse-transcribed (RT) with random hexamer primer using the High Capacity cDNA Archive kit for RT-PCR (Perkin-Elmer-Applied Biosystems Prism, Austin, TX). Real-time RT-PCR was carried out in a MX3005P (Stratagene, Cedar Creek, TX) thermocycler using Taqman Universal PCR Master Mix (Perkin-Elmer-Applied Biosystems). Absolute levels of Ao mRNA were quantified using 21-base sense (5'AGCACGACTTCCTGACTTGGA-3') and antisense primers (5'TTGTAGGATCCCCGATTTCC-3'), which span the second intron of the genomic sequence and produce an 88 base-pair amplicon. Amplification of Ao DNA was performed using oligonucleotide (6FAM-5'-CCGTCTGACCCTGCCGCAGC-3'-TAMRA), as the reporter probe. Parallel reactions, yeast RNA (carrier RNA) spiked with known amounts of synthetic Ao RNA, were used to convert sample determinations to absolute values. Ao primers and reporters were multiplexed with GAPDH, for a "house-keeper" mRNA (proprietary reagents supplied by Perkin-Elmer-Applied Biosystems). The multiplexing was used to control for RNA loading, degradation and PCR efficiency.

\section{Statistical analysis}

Data are presented as the mean \pm the standard error of the mean (SEM). Significant differences among groups were estimated by one-way ANOVA followed by Tukey's multiple comparison test (Instat 3.06, GraphPad Software Inc., La Jolla, CA). A value of $\mathrm{P}<0.05$ was considered to denote statistical significance.

\section{Results}

\subsection{Caveolae disruption by $M \beta C D$ or knockdown of Cav-3 by siRNA activates Ao gene expression}

$\mathrm{M} \beta C D$ has been consistently used as a pharmacological tool to study the role of lipid rafts/ caveolae in cardiac myocytes and other cellular models [15-17]. In NRVM with lipid rafts/ caveolae labeled with cholera toxin-B (CT-B), MBCD treatment induced detectable disruption of these plasma membrane structures within $10 \mathrm{~min}$ (Fig. 1A). To test whether caveolae may couple to regulation of Ao gene expression, NRVM were treated with $5 \mathrm{mM}$ 
of $M \beta C D$ for different times $(0-8 \mathrm{~h}) . \mathrm{M} \beta C D$ treatment increased Ao gene expression in a time-dependent manner, with significant changes in Ao gene expression initially observed at $4 \mathrm{~h}(2.16 \pm 0.17$ fold, $\mathrm{P}<0.01)$ (Fig. 1B). To determine the role of caveolae in regulation of Ao gene expression, we selectively knocked down the expression of Cav-3 protein (dominant isoform in cardiac myocyte) by transfecting NRVM with Cav-3 siRNA duplex. Fig 1C shows an immunoblot probed for Cav-3 protein in NRVM cell lysates harvested after $48 \mathrm{~h}$ transfection with Cav-3 specific siRNA. Cav-3 expression was efficiently knockeddown by transfection with Cav-3 siRNA, however, transfection with a control random sequence siRNA (con siRNA) did not affect the expression of Cav-3 (Fig 1C). siRNAmediated knockdown of Cav-3 protein significantly increased Ao gene expression (2.31 \pm 0.18 fold, $\mathrm{P}<0.01$ ) (Fig. 1D). In contrast, adenovirus-mediated overexpression of Cav-3 (Fig. 1E) decreased Ao gene expression, compared to cells overexpressing control vector (GFP) (Fig. 1F).

\subsection{Caveolae disruption by $M \beta C D$ or knockdown of Cav-3 by siRNA activates ERK, JNK and p38}

We compared the time-course of p38 and JNK activation with that of ERK1/2 in NRVM treated with $\mathrm{M} \beta C D$ (Fig. 2). Within 2 min of $M \beta C D$ treatment, there were significant increases in phosphorylation of ERK ( $1.32 \pm 0.039$ fold, $P<0.05)$, p38 (1.12 \pm 0.039 fold, $P<0.05)$ and JNK $(2.41 \pm 0.047$ fold, $P<0.001)(N=4)$, suggesting that caveolae/lipid rafts serve to maintain these MAP kinases in an inactive state. However, continued treatment with $\mathrm{M} \beta C D$ resulted in different activation patterns among the MAP kinases. M $\beta C D$-mediated ERK1/2 and p38 activation peaked at $2 \mathrm{~h},(5.23 \pm 0.48$ fold, $P<0.001$ and $4.98 \pm 0.23$ fold, $P<0.001$, respectively) and persisted up to $8 \mathrm{~h}$ (final time point). In contrast to ERK and $\mathrm{p} 38$, JNK phosphorylation peaked early, within $10 \mathrm{~min}$ of treatment $(4.55 \pm 0.13, P<0.001)$ and declined. We also observed that prolonged treatment of $\mathrm{M} \beta C D$ down-regulated total ERK1/2 expression (Fig. 2A). However, further studies are required to establish the role of cholesterol depletion on ERK1/2 expression and to identify the underlying mechanism. To further confirm the role of caveolae in the differential regulation of MAP kinase phosphorylation, NRVM were transfected with Cav-3 siRNA or control siRNA. siRNAmediated knockdown of Cav-3 significantly increased ERK ( $1.51 \pm 0.085$ fold, $P<0.01)$ and p38 (1.82 \pm 0.21 fold, $P<0.01)$ phosphorylation (Fig. $2 \mathrm{G}$ and $2 \mathrm{H})$. However, no significant difference was observed in JNK phosphorylation (control siRNA vs. Cav-3 siRNA group). Thus, the pattern of Cav-3 siRNA-mediated JNK activation was similar to that observed with chronic M $B C D$ treatment. These data suggest that individual MAP kinase members have different roles in mediating caveolae regulated cellular events.

\section{3. $\beta_{1}$-integrin is required for $M \beta C D$-mediated MAP kinase activation}

We previously demonstrated that mechanical stretch-induced MAP kinase activation is $\beta_{1}$ integrin-dependent [5]. To test whether $\beta_{1}$-integrin may also be required for mediating M $\beta C D$-induced activation of MAP kinases, NRVM infected for $24 \mathrm{~h}$ with matched titers of recombinant adenoviruses that express either Tac- $\beta_{1 \mathrm{D}}$ or control (lac $Z$ ) transgenes, were treated with M $\beta C D$ for $1 \mathrm{~h}$. NRVM transfected with Tac- $\beta_{1}$ expressing adenovirus showed high cell surface expression (fluorescence intensity of Tac- $\beta_{1}$ ), compared to cells transfected with lac $Z$ as determined by flow cytometry (data not shown) [5]. Tac- $\beta_{1 D}$ functions as a dominant-negative for $\beta_{1 \mathrm{~A}}$ subunit, as well as the predominantly expressed $\beta_{1 \mathrm{D}}$ subunit in myocytes. Disruption of $\beta_{1}$-integrin signaling significantly inhibited M $\beta C D$-mediated activation of ERK1/2 (0.728 \pm 0.05 fold, $P<0.01)$, p38 (1.147 \pm 0.06 fold, $P<0.001)$ and JNK ( $1.80 \pm 0.04$ fold, $P<0.001)$ (Fig. 3$)$. These results indicate that $\beta_{1}$-integrin plays an integral role in the activation of ERK1/2, p38 and JNK following MBCD treatment. 


\section{4. $\beta_{1}$-integrin-dependent regulation of $M \beta C D$ induces $A o$ gene expression}

Because adenovirus-mediated over expression of dominant negative $\beta_{1}$-integrin (Tac- $\left.\beta_{1}\right)$ significantly inhibited M $\beta C D$-induced activation of MAP kinases, we tested whether inhibition of $\beta_{1}$-integrin signaling may also inhibit the effects of $M \beta C D$ on Ao gene expression. This postulate was tested by infecting NRVM with adenoviruses expressing either lac $Z$ (control) or dominant-negative $\beta_{1}$-integrin $\left(\right.$ Tac- $\left.\beta_{1}\right)$ prior to $M \beta C D$ treatment. Unexpectedly, Tac- $\beta_{1}$ significantly increased $M \beta C D$-induced Ao gene expression compared to lac $Z$ (control) expressing cells (3.04 \pm 0.61 fold, $\mathrm{P}<0.001)$ (Fig. 4).

\subsection{ERK is a negative regulator of $M \beta C D$ and Cav-3 siRNA-induced Ao gene expression}

To determine whether ERK may play a role in MBCD or Cav-3 siRNA-induced Ao gene expression, cells were pretreated with a specific ERK inhibitor U0126 $(10 \mu \mathrm{M})$ or PD98059 $(20 \mu \mathrm{M})$ for $1 \mathrm{~h}$ prior to M $\mathrm{CCD}$ treatment. Although U0126 did not affect basal Ao gene expression, it significantly enhanced the stimulatory effects of MBCD (1.84 \pm 0.50 fold, $\mathrm{P}<0.001)$ (Fig. 5A) and Cav-3 siRNA (1.20 \pm 0.34 fold, $\mathrm{P}<0.05)$ (Fig. 5C) on Ao gene expression, suggesting that ERK negatively regulates $\mathrm{M} \beta \mathrm{CD}$ or Cav-3 siRNA-induced Ao gene expression.

\subsection{Negative regulation of Ao gene expression by JNK is independent of caveolae}

To determine whether JNK may play a role in MBCD-induced Ao gene expression, cells were pretreated with a specific JNK inhibitor (20 $\mu \mathrm{M}$ SP600125) for $1 \mathrm{~h}$ before M $\beta C D$ treatment. Incubation with SP600125 increased basal Ao mRNA expression several fold $(10.0 \pm 0.77$ fold, $\mathrm{P}<0.001)$ (Fig. 5B), which was independent of MBCD treatment. Similar results were observed when Cav-3 siRNA transfected cells were treated with JNK inhibitor SP600125 (Fig. 5D). These results suggest that JNK regulates basal Ao gene expression in a caveolae-independent manner.

\section{7. $p 38$ mediates $M \beta C D$ or Cav-3 siRNA-induced Ao gene expression}

To test whether p38 may have a role in Ao gene expression in a caveolae-independent manner, cells were pretreated with SB202190 $(10 \mu \mathrm{M})$ or SB203580 $(10 \mu \mathrm{M})$, specific inhibitors of p38 MAP kinase for $1 \mathrm{~h}$ before M $\beta C D$ treatment. Both pharmacological p38 inhibitors significantly inhibited $M \beta C D$ treatment induced Ao gene expression, SB 202190 ( $2.57 \pm 0.34$ fold, $\mathrm{P}<0.001)$ and SB203580 ( $2.26 \pm 0.42$ fold, $\mathrm{P}<0.001)$ (Fig. 6A). Furthermore, pharmacological inhibition of p38 by SB202190 significantly inhibited Cav-3 siRNA-induced Ao gene expression ( $1.09 \pm 0.083$ fold, $\mathrm{P}<0.01)$ (Fig. 6B). To further confirm this observation, NRVM were transfected with adenoviruses expressing wild-type p38 or p38a-DN (dominant p38 isoform in cardiac myocytes). Expression of wild-type p38a significantly increased the M $\beta C D$-induced Ao gene expression (2.36 \pm 1.13 fold, $\mathrm{P}<0.001$ ) (Fig. 6C). Conversely, expression of dominant-negative p38a significantly inhibited MBCD-induced Ao gene expression (1.91 \pm 0.14 fold, $\mathrm{P}<0.001)$ (Fig. 6C), further indicating that $\mathrm{p} 38$ is a primary mediator of $\mathrm{M} \beta \mathrm{CD}$ treatment or Cav-3 siRNA-induced Ao gene expression in cardiac myocytes.

\section{8. p38 regulates Cav- 1 and Cav- 3 expression in cardiac myocytes}

MAP kinases regulate caveolin gene expression in various noncardiac cell types [18-20], however, regulatory effects of MAP kinases on Cav-1 and Cav-3 expression in cardiac myocytes have not been studied. We assessed the role of ERK1/2, p38 and JNK in the regulation of Cav-1 and Cav-3 expression in cardiac myocytes. To test the role of MAP kinases in Cav-1/Cav-3 expression, NRVM were incubated for $24 \mathrm{~h}$ with specific inhibitors for ERK (10 $\mu \mathrm{M}$ U0126), p38 (10 $\mu \mathrm{M}$ SB202190) and JNK (20 $\mu \mathrm{M}$ SP600125). Western blot and immunofluorescent staining revealed that NRVM express both Cav-1 and Cav-3, in 
which Cav-1 expression was much less compared to Cav-3 (Fig. 7A and 7B). Western blot analysis revealed that $\mathrm{p} 38$ increased both Cav-1 and Cav-3 gene expression in NRVM (Fig. 7C and 7D). However, Cav-1 and Cav-3 protein expression was independent of ERK and JNK activation (data not shown).

\section{Discussion}

To our knowledge, this is the first study to demonstrate a role for caveolae in the regulation of Ao gene expression. Numerous studies have unequivocally shown that the RAS plays an important role in the heart, under a variety of pathologic conditions [1,2]. Cardiac myocyte specific overexpression of Ao results in cellular remodeling and age-dependent cardiac dysfunction and failure [21]. Furthermore, adenovirus-mediated delivery of Ao antisense attenuates hypertension and cardiac hypertrophy [22]. Caveolae and caveolins have been implicated in the wide range of cardiac protection [14, 16, 23]. Given the cardioprotective role of caveolae, we hypothesized that caveolae may suppress Ao gene expression in cardiac myocytes. Results from the present study indicate that chemical disruption of caveolae by $\mathrm{M} \beta C D$ induces Ao gene expression in a time-dependent manner, and requires $\beta_{1}$-integrin and p38 MAP kinase. However, ERK1/2 was identified as a negative regulator of this response. These findings suggest that caveolae-mediated cardiac protection may be due to suppression of Ao production by cardiac myocytes.

Disruption of caveolae/caveolin induces hyperactivation of the ERK pathway [24], which is thought to be responsible for hypertrophic growth. However, experimental evidence confirming such a mechanism is lacking. Although ERK activation has been mostly implicated in response to caveolae or caveolin modulation, other MAP kinase members, such as p38 and JNK, are known to be activated by modulation of caveolae/caveolins in various cell types as well [25].

Caveolae-mediated MAP kinase activation has been implicated in many diseases in various systems; however, the molecular activation mechanisms remain to be completely explored. In the present study, an unexpected finding was the identification of $\beta_{1}$-integrin as a major receptor required for the activation of MAP kinases in response to caveolae disruption. Caveolins and $\beta_{1}$-integrins colocalize within caveolae in the basal condition in cardiac myocytes, and caveolae disruption stimulates translocation of integrins from caveolae to noncaveolar sites within the membrane [12]. Because caveolae are flask-shaped invaginations located at cell surfaces [26], it is unlikely that integrins bind to ECM when located within caveolae. Together, these findings suggest that caveolae sequesters $\beta_{1^{-}}$ integrin, effectively preventing $\beta_{1}$-integrin from interacting with the ECM. Thus, disruption of caveolae activates $\beta_{1}$-integrin signaling by translocating $\beta_{1}$-integrin to non-caveolar sites within the membrane, which facilitate $\beta_{1}$-ECM interaction. However, further studies are required to identify the underlying mechanisms of caveolae-mediated sequestration of $\beta_{1^{-}}$ integrin.

Several equally robust studies conducted in cultured cardiac myocytes and transgenic animal models reported paradoxical roles for $\beta_{1}$-integrin in the myocardium [27-32]. For example, wild-type (WT) and $\beta_{1}$-integrin heterozygous knockout (hKO) mice studies reveal that a deficiency of $\beta_{1}$-integrin results in increased myocardial dysfunction after myocardial infarction [33], suggesting the protective nature of $\beta_{1}$-integrin in the myocardium. Consistent with these observations, $\beta_{1}$-integrin signaling has been reported to protect cardiac myocytes against $\beta_{1}$-adrenergic-stimulated apoptosis [27]. Moreover, cardiac myocytespecific excision of the $\beta_{1}$-integrin gene results in myocardial fibrosis and cardiac failure [30]. In contrast, other studies have shown that $\beta_{1}$-integrin mediates cardiac hypertrophy $[29,31,32]$. Thus, taken together these studies suggest that $\beta_{1}$-integrin has dichotomous 
regulatory functions in the myocardium. In light of the conflicting reports regarding protective and maladaptive roles of $\beta_{1}$-integrin in the heart, it was not too surprising to observe that expression of Tac- $\beta_{1}$ further increased M $\beta C D$-induced Ao gene expression. Taken together, these results indicate that $\beta_{1}$-integrin regulates M $\beta C D$-induced Ao gene expression via MAP kinase dependent and independent pathways.

Myocardial ERK1/2 activation is increased during cardiac hypertrophy [34] and hyperactivation of the ERK cascade is implicated in mediating the pathological effects caused by disruption of caveolae/caveolin [24, 35, 36]. Thus, an unexpected finding of the present study was the finding that ERK1/2 is a negative regulator of Ao gene expression in NRVM, as demonstrated by disruption of caveolae using M $\beta C D$. Recent studies using genetically-modified mice suggest that ERK1/2 signaling is not required for mediating physiologic or pathologic cardiac hypertrophy, although it may play a protective role in response to pathologic stimuli [37,38]. The mechanisms by which ERK1/2 negatively regulates Ao gene expression in the myocardium remain to be identified. The observation that JNK negatively regulates Ao gene expression is consistent with studies, which suggest a protective role for the JNK cascade in the myocardium [39-42]. p38 has been implicated in both cardiac protection and injury [42-44]. However, the molecular basis for the divergent functions of p38 activation is unknown and requires further investigation. The finding that p38 mediates M $\beta C D$-induced Ao gene expression is consistent with recent reports suggesting that p38 may induce maladaptive effects in the myocardium [42-45]. Studies using pharmacological inhibitors [46-49] and genetic manipulations [42, 44] suggest a detrimental role for $\mathrm{p} 38$ in mediating events associated with cardiac hypertrophy, remodeling and contractile dysfunction. The downstream effectors responsible for mediating p38 effects on Ao gene expression remain to be identified.

Results from this study suggest that upregulation of $\mathrm{Cav}-1$ and $\mathrm{Cav}-3$ protein expression by p38 indirectly serves as an important negative feedback system by sequestering p38 to the plasma membrane via caveolin, thereby playing a cardioprotective role. Similar results have been shown in vascular smooth muscle cells, in which p38 activation also upregulates Cav-1 expression [19, 20]. Interestingly, in the present study, ERK and JNK, negative regulators of Ao gene expression in NRVM, had no effect on Cav-1 and Cav-3 protein expression. This is in contrast to H-Ras (G12V)-transformed NIH3T3 cells, in which increased expression of ERK caused down regulation of Cav-1 [50]. However, differential regulation of caveolins among cell types has been reported [51] and may relate to the pathophysiological state of the tissue. The biochemical and molecular mechanisms responsible for regulation of caveolin expression remain to be further explored in the myocardium.

\section{Limitations}

Currently, $\mathrm{M} \beta C D$ is the primary method to induce acute disruption of both lipid rafts and caveolae. Although complementary molecular approaches were also used to verify specificity of M $\beta C D$ and $\mathrm{Cav}-3$ on signaling effects and Ao expression, some subtle effects may have been mediated through single and/or clustered lipid rafts as well. A better understanding of signaling events mediated by lipid rafts and caveolae will become possible as new technologies are developed to better determine the composition and function of these membrane structures.

\section{Conclusion}

In summary, these results suggest that lipid rafts/caveolae have an important role in maintaining basal Ao gene expression in cardiac myocytes and that activation of MAP kinases ERK, p38 and JNK, caused by caveolae disruption, requires $\beta_{1}$-integrin function. These observations provide new insights into the importance of caveolae in controlling 
cardiac growth. The finding that only p38 kinase was required for M $\beta C D$-induced upregulation of Ao gene expression suggests that targeting the p38 pathway may provide a therapeutic regimen for protecting the injured myocardium.

\section{Acknowledgments}

The authors of this manuscript have certified that they comply with the principles of ethical publishing in the International Journal of Cardiology [52]. This work was supported by a grant from the National Institutes of Health (HL-68838), Department of Veterans Affairs (1I01BX000801) and Scott and White Hospital.

\section{References}

1. Barlucchi L, Leri A, Dostal DE, Fiordaliso F, Tada H, Hintze TH, et al. Canine ventricular myocytes possess a renin-angiotensin system that is upregulated with heart failure. Circ Res. 2001; 88:298-304. [PubMed: 11179197]

2. Brooks WW, Bing OH, Conrad CH, O'Neill L, Crow MT, Lakatta EG, et al. Captopril modifies gene expression in hypertrophied and failing hearts of aged spontaneously hypertensive rats. Hypertension. 1997; 30:1362-8. [PubMed: 9403554]

3. Jorde UP. Suppression of the renin-angiotensin-aldosterone system in chronic heart failure: choice of agents and clinical impact. Cardiol Rev. 2006; 14:81-7. [PubMed: 16493245]

4. Xu J, Carretero OA, Lin CX, Cavasin MA, Shesely EG, Yang JJ, et al. Role of cardiac overexpression of ANG II in the regulation of cardiac function and remodeling postmyocardial infarction. Am J Physiol Heart Circ Physiol. 2007; 293:H1900-7. [PubMed: 17586619]

5. Lal H, Verma SK, Smith M, Guleria RS, Lu G, Foster DM, et al. Stretch-induced MAP kinase activation in cardiac myocytes: differential regulation through beta1-integrin and focal adhesion kinase. J Mol Cell Cardiol. 2007; 43:137-47. [PubMed: 17583725]

6. Lal H, Verma SK, Golden HB, Foster DM, Smith M, Dostal DE. Stretch-induced regulation of angiotensinogen gene expression in cardiac myocytes and fibroblasts: Opposing roles of JNK1/2 and p38alpha MAP kinases. J Mol Cell Cardiol. 2008

7. Anderson RG. Caveolae: where incoming and outgoing messengers meet. Proc Natl Acad Sci U S A. 1993; 90:10909-13. [PubMed: 8248193]

8. Tang Z, Scherer PE, Okamoto T, Song K, Chu C, Kohtz DS, et al. Molecular cloning of caveolin-3, a novel member of the caveolin gene family expressed predominantly in muscle. J Biol Chem. 1996; 271:2255-61. [PubMed: 8567687]

9. Cohen AW, Hnasko R, Schubert W, Lisanti MP. Role of caveolae and caveolins in health and disease. Physiol Rev. 2004; 84:1341-79. [PubMed: 15383654]

10. Williams TM, Lisanti MP. The Caveolin genes: from cell biology to medicine. Ann Med. 2004; 36:584-95. [PubMed: 15768830]

11. Patel HH, Murray F, Insel PA. Caveolae as organizers of pharmacologically relevant signal transduction molecules. Annu Rev Pharmacol Toxicol. 2008; 48:359-91. [PubMed: 17914930]

12. Radel C, Carlile-Klusacek M, Rizzo V. Participation of caveolae in beta1 integrin-mediated mechanotransduction. Biochem Biophys Res Commun. 2007; 358:626-31. [PubMed: 17498653]

13. Kawabe J, Okumura S, Lee MC, Sadoshima J, Ishikawa Y. Translocation of caveolin regulates stretch-induced ERK activity in vascular smooth muscle cells. Am J Physiol Heart Circ Physiol. 2004; 286:H1845-52. [PubMed: 15072971]

14. Patel HH, Tsutsumi YM, Head BP, Niesman IR, Jennings M, Horikawa Y, et al. Mechanisms of cardiac protection from ischemia/reperfusion injury: a role for caveolae and caveolin-1. Faseb J. 2007; 21:1565-74. [PubMed: 17272740]

15. Balijepalli RC, Foell JD, Hall DD, Hell JW, Kamp TJ. Localization of cardiac L-type Ca(2+) channels to a caveolar macromolecular signaling complex is required for beta(2)-adrenergic regulation. Proc Natl Acad Sci U S A. 2006; 103:7500-5. [PubMed: 16648270]

16. Horikawa YT, Patel HH, Tsutsumi YM, Jennings MM, Kidd MW, Hagiwara Y, et al. Caveolin-3 expression and caveolae are required for isoflurane-induced cardiac protection from hypoxia and ischemia/reperfusion injury. J Mol Cell Cardiol. 2008; 44:123-30. [PubMed: 18054955] 
17. Sedding DG, Hermsen J, Seay U, Eickelberg O, Kummer W, Schwencke C, et al. Caveolin-1 facilitates mechanosensitive protein kinase B (Akt) signaling in vitro and in vivo. Circ Res. 2005; 96:635-42. [PubMed: 15731459]

18. Dasari A, Bartholomew JN, Volonte D, Galbiati F. Oxidative stress induces premature senescence by stimulating caveolin-1 gene transcription through $\mathrm{p} 38$ mitogen-activated protein kinase/Sp1mediated activation of two GC-rich promoter elements. Cancer Res. 2006; 66:10805-14. [PubMed: 17108117]

19. Engelman JA, Zhang XL, Razani B, Pestell RG, Lisanti MP. p42/44 MAP kinase-dependent and independent signaling pathways regulate caveolin-1 gene expression. Activation of Ras-MAP kinase and protein kinase a signaling cascades transcriptionally down-regulates caveolin-1 promoter activity. J Biol Chem. 1999; 274:32333-41. [PubMed: 10542274]

20. Kim HP, Wang X, Nakao A, Kim SI, Murase N, Choi ME, et al. Caveolin-1 expression by means of p38beta mitogen-activated protein kinase mediates the antiproliferative effect of carbon monoxide. Proc Natl Acad Sci U S A. 2005; 102:11319-24. [PubMed: 16051704]

21. Domenighetti AA, Wang Q, Egger M, Richards SM, Pedrazzini T, Delbridge LM. Angiotensin IImediated phenotypic cardiomyocyte remodeling leads to age-dependent cardiac dysfunction and failure. Hypertension. 2005; 46:426-32. [PubMed: 15998712]

22. Kimura B, Mohuczy D, Tang X, Phillips MI. Attenuation of hypertension and heart hypertrophy by adeno-associated virus delivering angiotensinogen antisense. Hypertension. 2001; 37:376-80. [PubMed: 11230303]

23. Patel HH, Head BP, Petersen HN, Niesman IR, Huang D, Gross GJ, et al. Protection of adult rat cardiac myocytes from ischemic cell death: role of caveolar microdomains and delta-opioid receptors. Am J Physiol Heart Circ Physiol. 2006; 291:H344-50. [PubMed: 16501018]

24. Cohen AW, Park DS, Woodman SE, Williams TM, Chandra M, Shirani J, et al. Caveolin-1 null mice develop cardiac hypertrophy with hyperactivation of p42/44 MAP kinase in cardiac fibroblasts. Am J Physiol Cell Physiol. 2003; 284:C457-74. [PubMed: 12388077]

25. Wang XM, Zhang Y, Kim HP, Zhou Z, Feghali-Bostwick CA, Liu F, et al. Caveolin-1: a critical regulator of lung fibrosis in idiopathic pulmonary fibrosis. J Exp Med. 2006; 203:2895-906. [PubMed: 17178917]

26. Stan RV. Structure of caveolae. Biochim Biophys Acta. 2005; 1746:334-48. [PubMed: 16214243]

27. Communal C, Singh M, Menon B, Xie Z, Colucci WS, Singh K. beta1 integrins expression in adult rat ventricular myocytes and its role in the regulation of beta-adrenergic receptor-stimulated apoptosis. J Cell Biochem. 2003; 89:381-8. [PubMed: 12704801]

28. Krishnamurthy P, Subramanian V, Singh M, Singh K. Beta1 integrins modulate beta-adrenergic receptor-stimulated cardiac myocyte apoptosis and myocardial remodeling. Hypertension. 2007; 49:865-72. [PubMed: 17283249]

29. Ross RS, Pham C, Shai SY, Goldhaber JI, Fenczik C, Glembotski CC, et al. Beta1 integrins participate in the hypertrophic response of rat ventricular myocytes. Circ Res. 1998; 82:1160-72. [PubMed: 9633916]

30. Shai SY, Harpf AE, Babbitt CJ, Jordan MC, Fishbein MC, Chen J, et al. Cardiac myocyte-specific excision of the beta1 integrin gene results in myocardial fibrosis and cardiac failure. Circ Res. 2002; 90:458-64. [PubMed: 11884376]

31. Pham CG, Harpf AE, Keller RS, Vu HT, Shai SY, Loftus JC, et al. Striated muscle-specific beta(1D)-integrin and FAK are involved in cardiac myocyte hypertrophic response pathway. Am $\mathbf{J}$ Physiol Heart Circ Physiol. 2000; 279:H2916-26. [PubMed: 11087248]

32. Yutao X, Geru W, Xiaojun B, Tao G, Aiqun M. Mechanical stretch-induced hypertrophy of neonatal rat ventricular myocytes is mediated by beta(1)-integrin-microtubule signaling pathways. Eur J Heart Fail. 2006; 8:16-22. [PubMed: 16198630]

33. Krishnamurthy P, Subramanian V, Singh M, Singh K. Deficiency of beta1 integrins results in increased myocardial dysfunction after myocardial infarction. Heart. 2006; 92:1309-15. [PubMed: 16547211]

34. Bueno OF, Molkentin JD. Involvement of extracellular signal-regulated kinases $1 / 2$ in cardiac hypertrophy and cell death. Circ Res. 2002; 91:776-81. [PubMed: 12411391] 
35. Park DS, Woodman SE, Schubert W, Cohen AW, Frank PG, Chandra M, et al. Caveolin-1/3 double-knockout mice are viable, but lack both muscle and non-muscle caveolae, and develop a severe cardiomyopathic phenotype. Am J Pathol. 2002; 160:2207-17. [PubMed: 12057923]

36. Woodman SE, Park DS, Cohen AW, Cheung MW, Chandra M, Shirani J, et al. Caveolin-3 knockout mice develop a progressive cardiomyopathy and show hyperactivation of the p42/44 MAPK cascade. J Biol Chem. 2002; 277:38988-97. [PubMed: 12138167]

37. Maillet M, Purcell NH, Sargent MA, York A, Bueno OF, Molkentin JD. Dusp6 (MKP3) null mice show enhanced ERK1/2 phosphorylation at baseline and increased myocyte proliferation in the heart affecting disease susceptibility. J Biol Chem. 2008

38. Purcell NH, Wilkins BJ, York A, Saba-El-Leil MK, Meloche S, Robbins J, et al. Genetic inhibition of cardiac ERK1/2 promotes stress-induced apoptosis and heart failure but has no effect on hypertrophy in vivo. Proc Natl Acad Sci U S A. 2007; 104:14074-9. [PubMed: 17709754]

39. Engelbrecht AM, Niesler C, Page C, Lochner A. p38 and JNK have distinct regulatory functions on the development of apoptosis during simulated ischaemia and reperfusion in neonatal cardiomyocytes. Basic Res Cardiol. 2004; 99:338-50. [PubMed: 15309413]

40. Liang Q, Molkentin JD. Redefining the roles of p38 and JNK signaling in cardiac hypertrophy: dichotomy between cultured myocytes and animal models. J Mol Cell Cardiol. 2003; 35:1385-94. [PubMed: 14654364]

41. Tachibana H, Perrino C, Takaoka H, Davis RJ, Naga Prasad SV, Rockman HA. JNK1 is required to preserve cardiac function in the early response to pressure overload. Biochem Biophys Res Commun. 2006; 343:1060-6. [PubMed: 16579967]

42. Wang Y. Mitogen-activated protein kinases in heart development and diseases. Circulation. 2007; 116:1413-23. [PubMed: 17875982]

43. Bassi R, Heads R, Marber MS, Clark JE. Targeting p38-MAPK in the ischaemic heart: kill or cure? Curr Opin Pharmacol. 2008; 8:141-6. [PubMed: 18289939]

44. Liao P, Georgakopoulos D, Kovacs A, Zheng M, Lerner D, Pu H, et al. The in vivo role of p38 MAP kinases in cardiac remodeling and restrictive cardiomyopathy. Proc Natl Acad Sci U S A. 2001; 98:12283-8. [PubMed: 11593045]

45. Park JK, Fischer R, Dechend R, Shagdarsuren E, Gapeljuk A, Wellner M, et al. p38 mitogenactivated protein kinase inhibition ameliorates angiotensin II-induced target organ damage. Hypertension. 2007; 49:481-9. [PubMed: 17224470]

46. Bao W, Behm DJ, Nerurkar SS, Ao Z, Bentley R, Mirabile RC, et al. Effects of p38 MAPK Inhibitor on angiotensin II-dependent hypertension, organ damage, and superoxide anion production. J Cardiovasc Pharmacol. 2007; 49:362-8. [PubMed: 17577100]

47. Kompa AR, See F, Lewis DA, Adrahtas A, Cantwell DM, Wang BH, et al. Long-term but not short-term p38 mitogen-activated protein kinase inhibition improves cardiac function and reduces cardiac remodeling post-myocardial infarction. J Pharmacol Exp Ther. 2008; 325:741-50. [PubMed: 18334667]

48. Matsuyama D, Kawahara K. Proliferation of neonatal cardiomyocytes by connexin 43 knockdown via synergistic inactivation of p38 MAPK and increased expression of FGF1. Basic Res Cardiol. 2009

49. Sy JC, Seshadri G, Yang SC, Brown M, Oh T, Dikalov S, et al. Sustained release of a p38 inhibitor from non-inflammatory microspheres inhibits cardiac dysfunction. Nat Mater. 2008; 7:863-8. [PubMed: 18931671]

50. Engelman JA, Chu C, Lin A, Jo H, Ikezu T, Okamoto T, et al. Caveolin-mediated regulation of signaling along the p42/44 MAP kinase cascade in vivo. A role for the caveolin-scaffolding domain. FEBS Lett. 1998; 428:205-11. [PubMed: 9654135]

51. Kathuria H, Cao YX, Ramirez MI, Williams MC. Transcription of the caveolin-1 gene is differentially regulated in lung type I epithelial and endothelial cell lines. A role for ETS proteins in epithelial cell expression. J Biol Chem. 2004; 279:30028-36. [PubMed: 15138262]

52. Coats AJ. Ethical authorship and publishing. Int J Cardiol. 2009; 131:149-50. [PubMed: 19046787] 

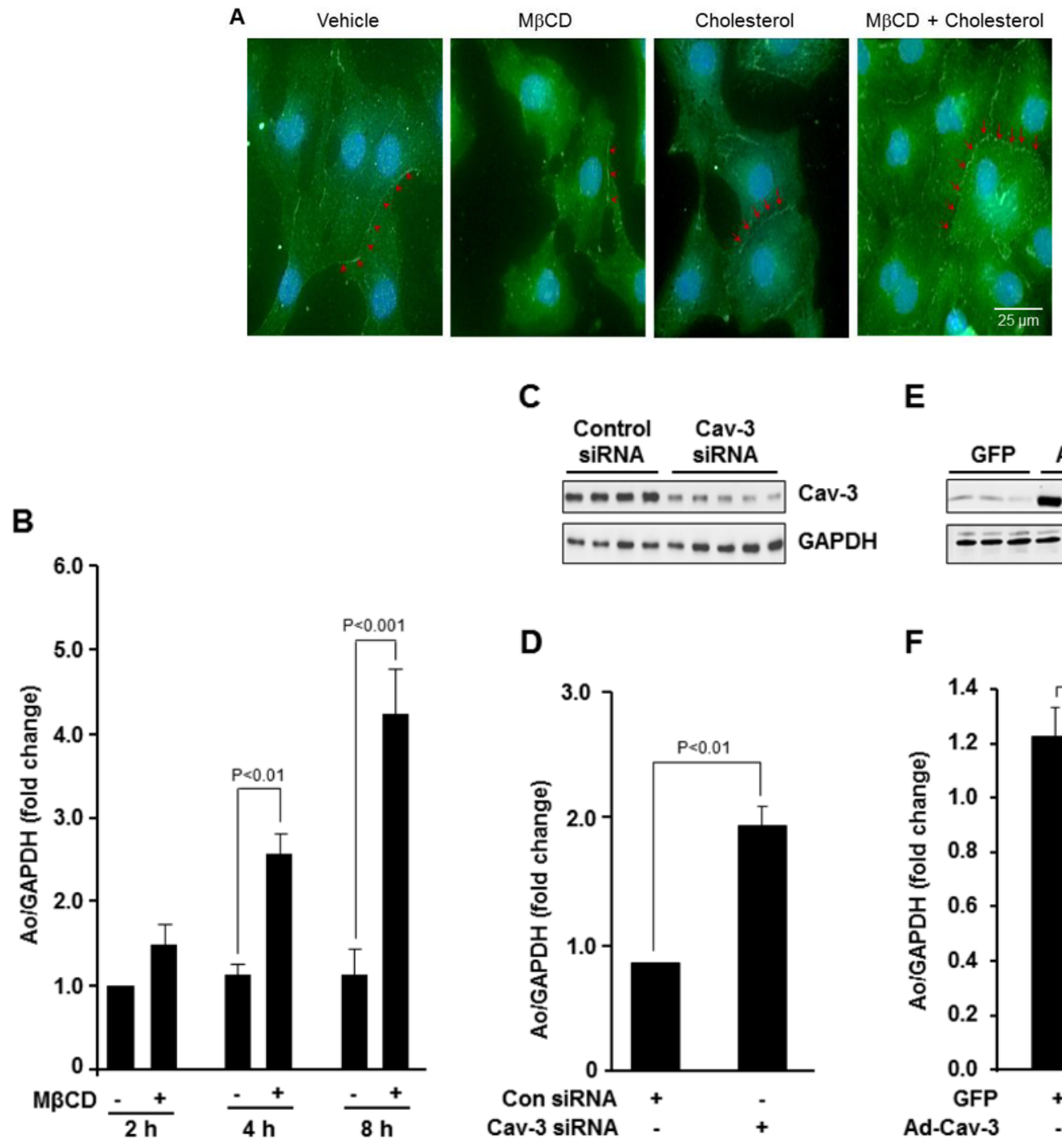

C

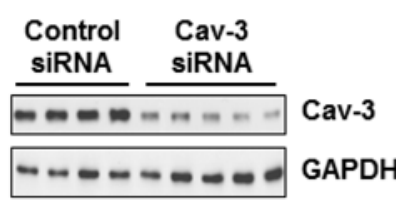

D

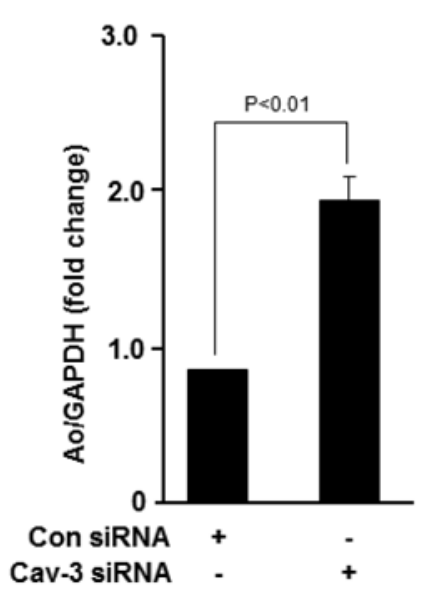

$\mathbf{E}$

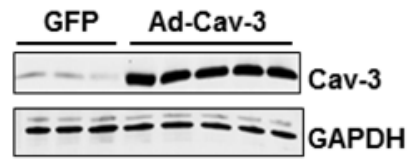

$\mathbf{F}$

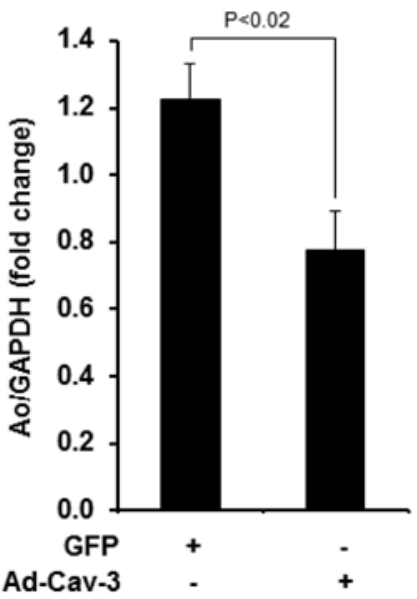

Figure 1. Caveolae disruption by MBCD or siRNA-mediated knockdown of Cav-3 upregulates Ao gene expression

Prior to treatment for $10 \mathrm{~min}$ with $5 \mathrm{mM} \mathrm{M \beta CD}$ and/or $1 \mathrm{mM}$ cholesterol, lipid rafts/ caveolae were labeled by incubating cells for $10 \mathrm{~min}$ in culture medium containing $1 \mu \mathrm{g} / \mathrm{ml}$ cholera toxin. The effects of $\mathrm{M} \beta C D$ and/or extracellular cholesterol on the integrity of lipid rafts in NRVM were visualized by immunofluorescent staining of cholera toxin (A). The location of intact lipid rafts/caveole is indicated by green arrows. Addition of cholesterol to the culture medium prevented the disruption of lipid rafts/caveolae by MBCD. For determinations of Ao gene expression, NRVM were treated with $\mathrm{M} \beta C D(5 \mathrm{mM})$ for various times $(2-8 \mathrm{~h})$, as indicated (B). After MBCD treatment, cells were harvested, RNA was isolated and expression of Ao mRNA was determined using real-time RT-PCR in a multiplex system with GAPDH (for normalization). The effects of siRNA-mediated downregulation of Cav-3 expression in NRVM, in which myocytes were transfected with either duplex siRNA (150 nM) targeted against Cav-3 (Cav-3 siRNA) or a random sequence (control siRNA) (C). $48 \mathrm{~h}$ after transfection, cells were harvested and protein levels were analyzed in immunoblots probed with a Cav-3 or GAPDH antibody (D). NRVM were also infected with adenovirus expressing GFP (control) or Cav-3 for $48 \mathrm{~h}$ (E). Cav-3 expression was verified using Western blot analysis and effects on Ao gene expression are also given 
(F). Results are expressed as means \pm SEM. $\mathrm{N}=4$ experiments. M $\beta C D$, methyl- $\beta$ cyclodextrin; Anti-CT, anti-cholera toxin antibody staining. 
A

C $\frac{M \beta C D(\min )}{2510153060} \quad M \beta C D \frac{2 \mathrm{~h}}{-+} \frac{4 \mathrm{~h}}{+} \frac{8 \mathrm{~h}}{+}$

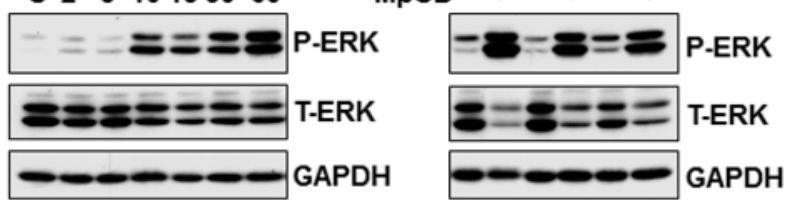

B

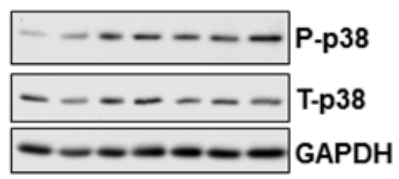

C

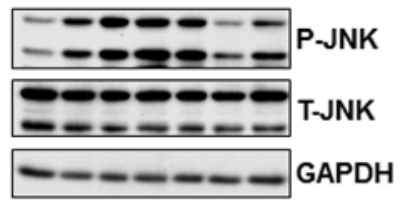

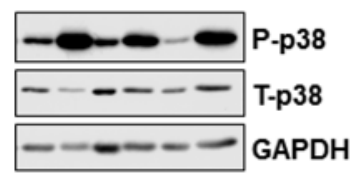

E

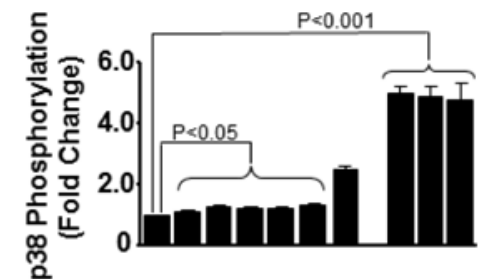

$\mathbf{F}$

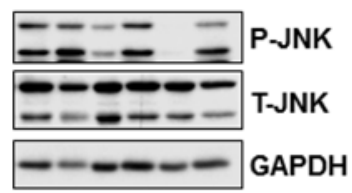

D
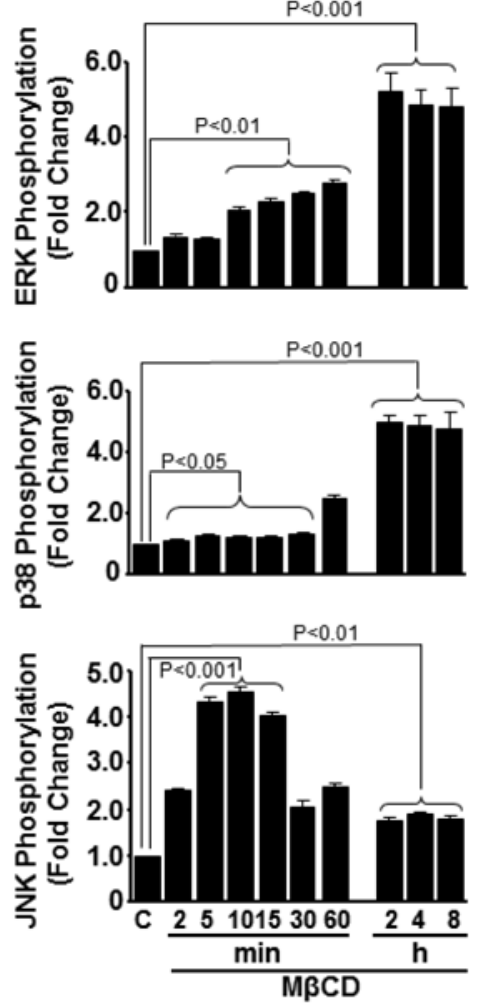

H

\begin{tabular}{|c|c|}
\hline ontrol SiRNA Cav-3 SiRNA & \\
\hline 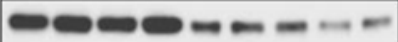 & Cav-3 \\
\hline$=-=-===0$ & P-ERK \\
\hline 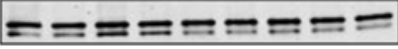 & T-ERK \\
\hline$--\cdots-\cdots-\cdots$ & P-p38 \\
\hline$-\cdots-\cdots$ & $T-p 38$ \\
\hline$-\equiv \equiv \equiv \equiv \equiv \equiv \equiv$ & P.JNK \\
\hline 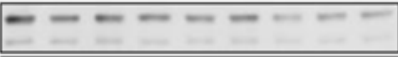 & JNK \\
\hline- & \\
\hline
\end{tabular}

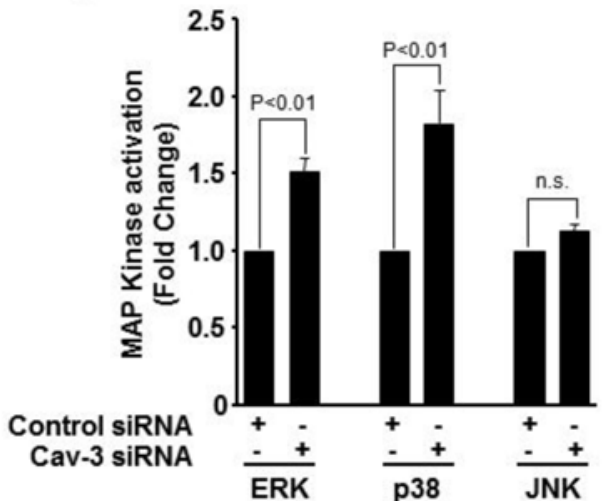


Figure 2. MAP kinases are activated by disruption of caveolae using MBCD or Cav-3 knockdown by SiRNA

NRVM were treated with MBCD (5 mM) for different times ( $2 \mathrm{~min}-8 \mathrm{~h})$, as indicated. After M $\mathrm{MCD}$ treatment, cells were harvested and lysates were analyzed by immunoblotting using phospho-ERK1/2, phospho-p38 and phospho-JNK antibodies, as indicated (A, B and C, respectively). Bar graphs show fold changes in ERK (D), p38 (E) and JNK (F) phosphorylation after M $\mathrm{MCD}$ treatment (D, E and F, respectively). The effects of siRNAmediated Cav-3 knockdown on MAP-kinase pathways via immunoblots prepared from cardiac myocytes transfected with siRNA targeted against Cav-3 or control siRNA are shown (G). Cell lysates were resolved by SDS-PAGE and analyzed in immunoblots probed with phospho and pan antibodies for ERK, p38 and JNK. Cav-3 and GAPDH expression were quantified in immunoblots probed with respective antibodies. Results of densitometric analyses from pooled data show levels of ERK, p38 and JNK phosphorylation in Cav-3 siRNA or control siRNA-transfected cells $(\mathrm{H})$. Results are expressed as means $\pm \mathrm{SEM} . \mathrm{N}=$ 4 experiments. M $\beta C D$, methyl- $\beta$-cyclodextrin; GAPDH, glyceraldehyde-3-phosphate dehydrogenase. 
A

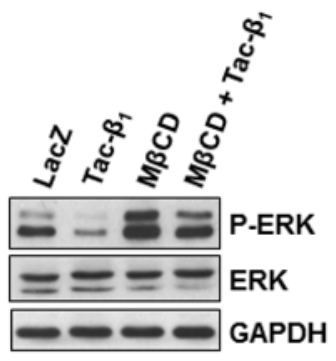

D

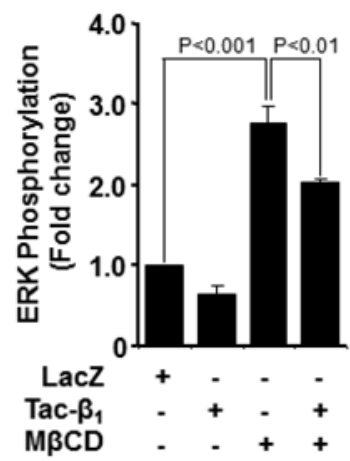

B

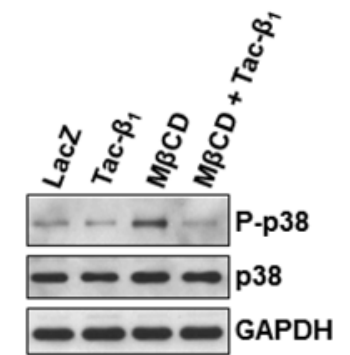

E

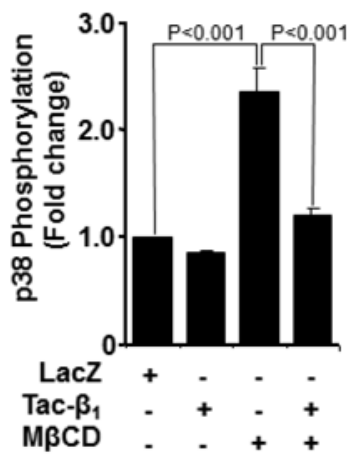

C

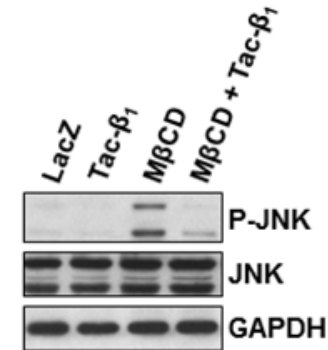

$\mathbf{F}$

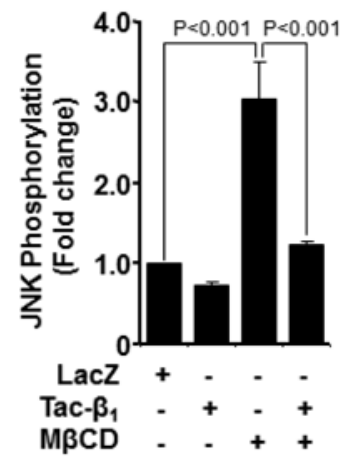

Figure 3. $\beta_{1}$-integrin is required for caveolae disruption-induced phosphorylation of ERK1/2, p38, and JNK

Prior to M $\beta C D$ treatment, NRVM were infected with adenovirus (24 h) which resulted in expression of Tac- $\beta_{1 \mathrm{D}}$ or control protein (lacZ). After $24 \mathrm{~h}$ of transfection, viral medium was replaced with serum free medium and allowed for overnight starvation before starting the M $\beta C D$ treatment. After M $\beta C D$ treatment (1 h), phosphorylation levels of ERK (A), p38 (B) and JNK (C) were determined. Bar graphs show fold changes in ERK (D), p38 (E) and JNK (F) phosphorylation after Tac- $\beta_{1 \mathrm{D}}$ expression compared to control virus. Values are means \pm SEM. $\mathrm{N}=4$ experiments. M $\beta C D$, methyl- $\beta$-cyclodextrin. 


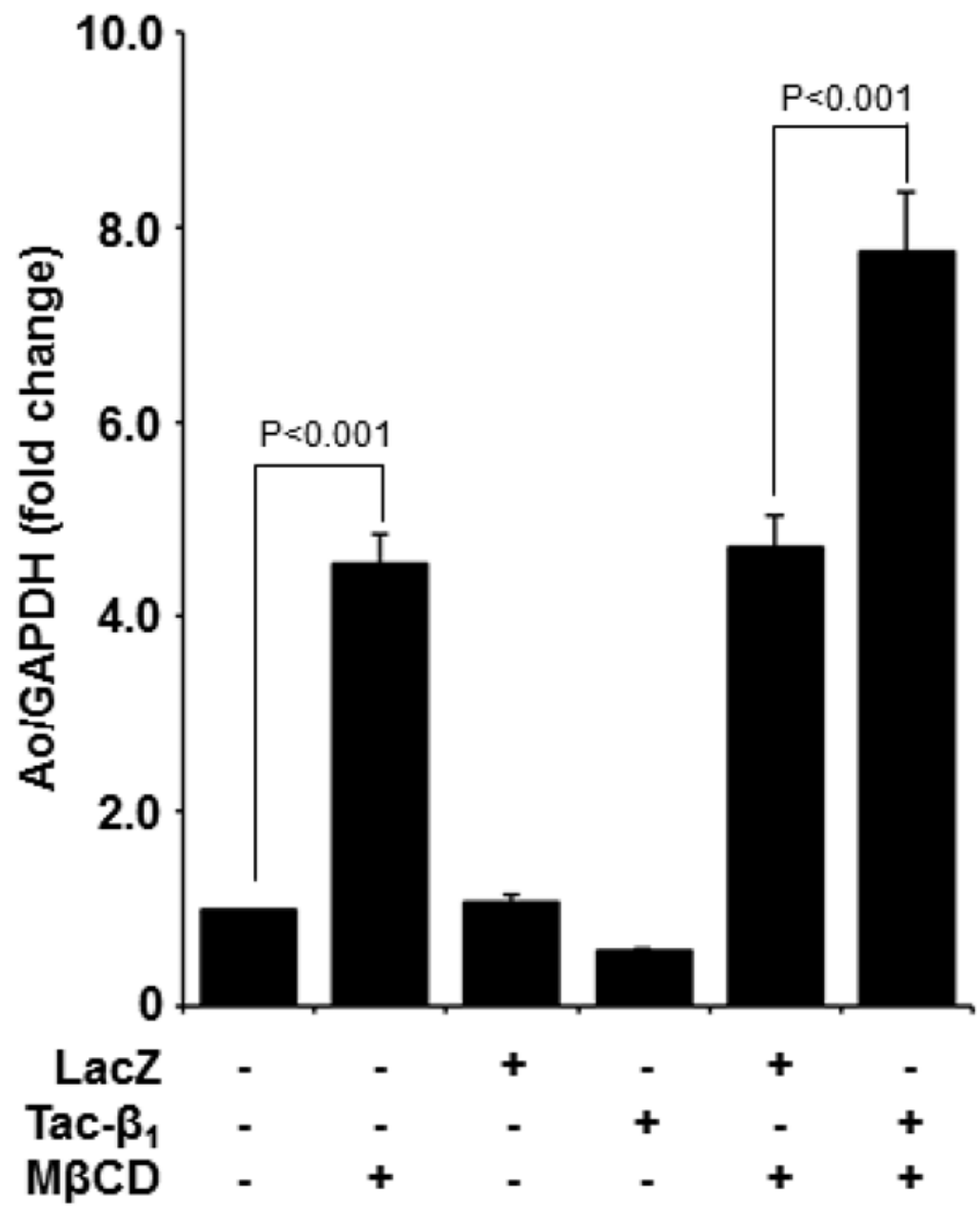

Figure 4. $\beta_{1}$-integrin dependent regulation of $M \beta C D$-induced Ao gene expression Prior to M $\beta C D$ treatment, NRVM were infected with adenovirus ( $24 \mathrm{~h}$ ) which resulted in expression of Tac- $\beta_{1 \mathrm{D}}$ or control protein (lacZ). After $24 \mathrm{~h}$ of transfection, viral medium was replaced with serum-free medium and allowed for overnight starvation before starting cyclodextrin treatment. After M $\beta C D$ treatment, cells were harvested and RNA was isolated, and expression of Ao mRNA was determined using real-time RT-PCR. Tac- $\beta_{1 D}$ expression decreased basal Ao gene expression in control cells, but significantly increased Ao gene expression in the cells treated with $\mathrm{M} \beta C D$. Results are expressed as means $\pm \mathrm{SEM}$. $\mathrm{N}=4$ experiments. $\mathrm{M} \beta C D$, methyl- $\beta$-cyclodextrin. 
A

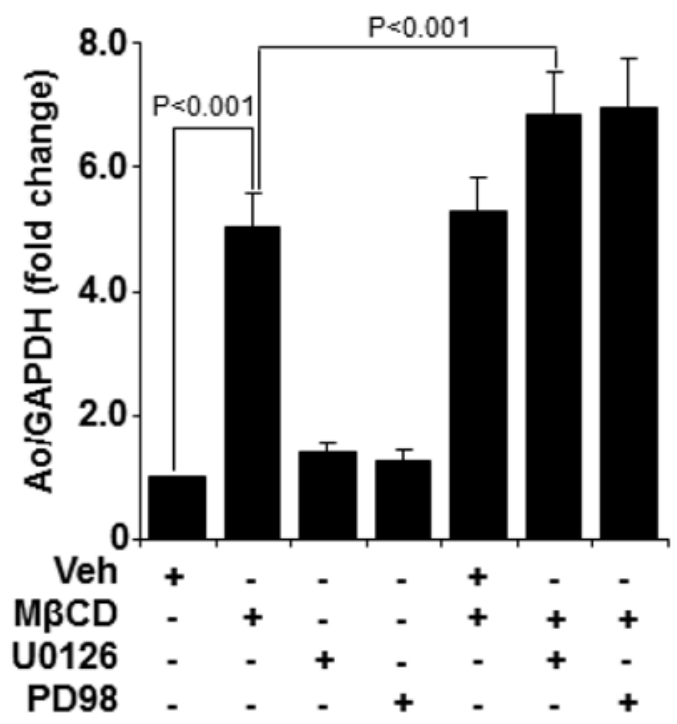

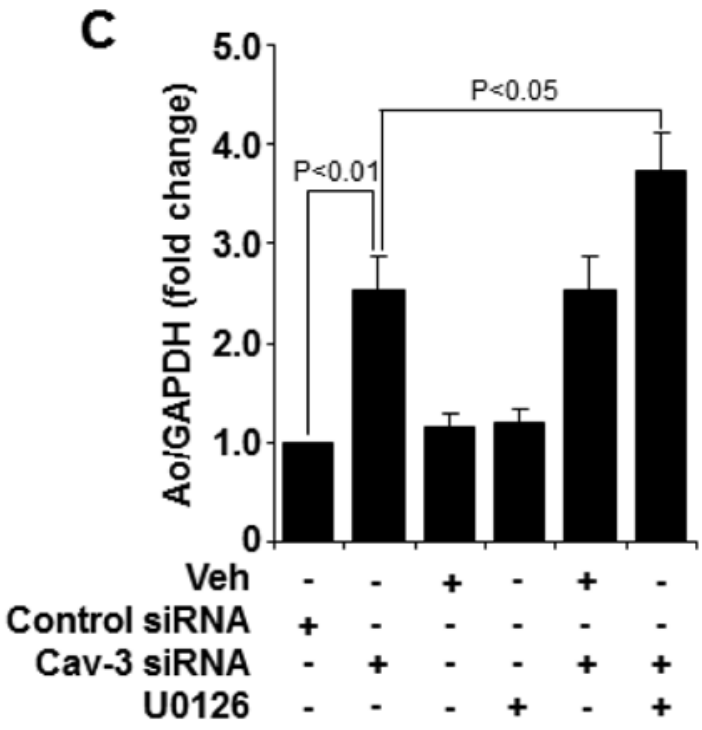

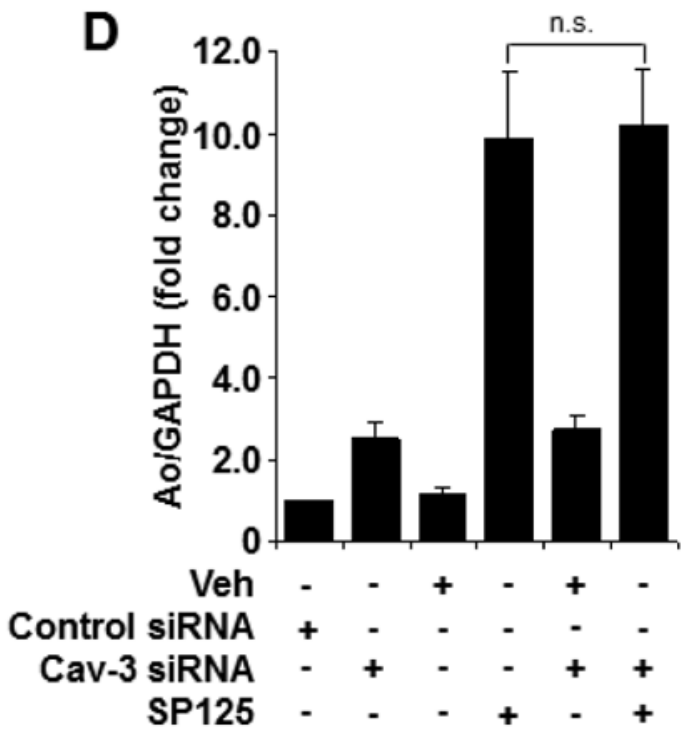

Figure 5. ERK negatively regulates $M \beta C D$ or Cav-3 siRNA-induced Ao gene expression, whereas JNK negatively regulates basal Ao gene expression independent of caveolae

NRVM were treated with MBCD in the presence and absence of specific MAP kinase cascade inhibitors (1 h pretreatment) for ERK (10 $\mu \mathrm{M}$ U0126) and JNK1/2 (20 $\mu \mathrm{M}$ SP600125) (A and B, respectively). After $8 \mathrm{~h}$ of M $\mathrm{MCD}$ treatment, cells were harvested, RNA was isolated and expression of Ao mRNA was determined using real-time RT-PCR. Control and Cav-3 siRNA transfected NRVM were incubated with inhibitors for ERK (10 $\mu \mathrm{M}$ U0126); JNK1/2 (20 $\mu \mathrm{M}$ SP600125) (C and D, respectively). After $8 \mathrm{~h}$ of incubation, cells were harvested, total RNA was isolated and Ao mRNA expression was determined using real-time RT-PCR. Results are expressed as means \pm SEM. $\mathrm{N}=4$ experiments. MßCD, methyl- $\beta$-cyclodextrin; PD98, PD98059; SP125, SP600125; Veh, vehicle. 
A

B

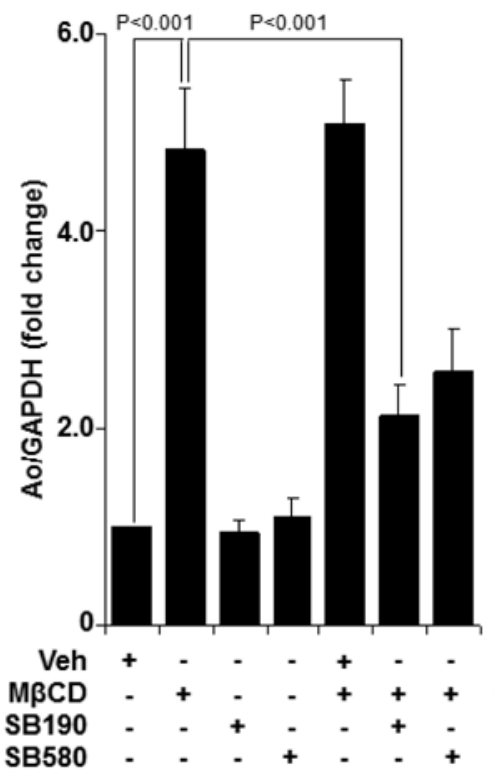

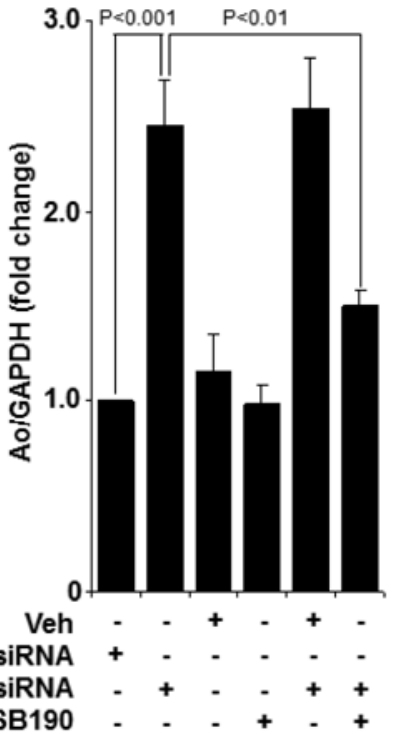

C

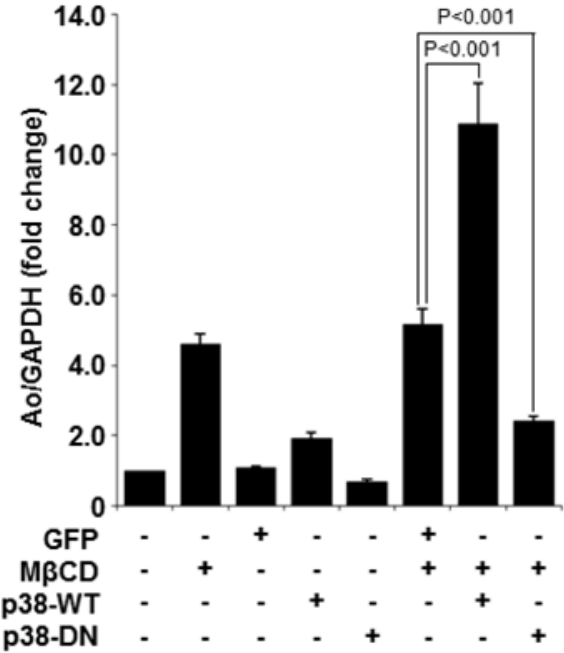

Figure 6. p38 mediates both $\mathrm{M} \beta C D$ and Cav-3 siRNA-induced Ao gene expression NRVM were treated with $\mathrm{M} \beta \mathrm{CD}$ in the presence and absence of specific p38 kinase inhibitors SB202190 $(10 \mu \mathrm{M})$ or SB203580 $(10 \mu \mathrm{M})(1 \mathrm{~h}$ pretreatment). After $8 \mathrm{~h}$ of M $\mathrm{MCD}$ treatment, cells were harvested, RNA was isolated and Ao mRNA expression was determined using real-time RT-PCR (A). Control and Cav-3 siRNA transfected NRVM were incubated with p38 inhibitor SB202190 $(10 \mu \mathrm{M})$. After $8 \mathrm{~h}$ of treatment, cells were harvested, RNA was isolated and Ao mRNA expression was determined. Cells were transfected with adenoviruses expressing wild-type (p38-WT) and dominant-negative (p38$\mathrm{DN}$ ) forms of $\mathrm{p} 38 \mathrm{a}(\mathrm{B})$. After $24 \mathrm{~h}$, the viral medium was replaced with serum-free medium and cells were starved overnight prior to MBCD treatment. After MBCD treatment, cells were harvested and RNA was isolated, and expression of Ao was determined (C). Results are expressed as means \pm SEM. $N=4$ experiments. M $\beta C D$, methyl- $\beta$-cyclodextrin; SB190, SB20190; SB580, SB203580; Veh, vehicle. 
A
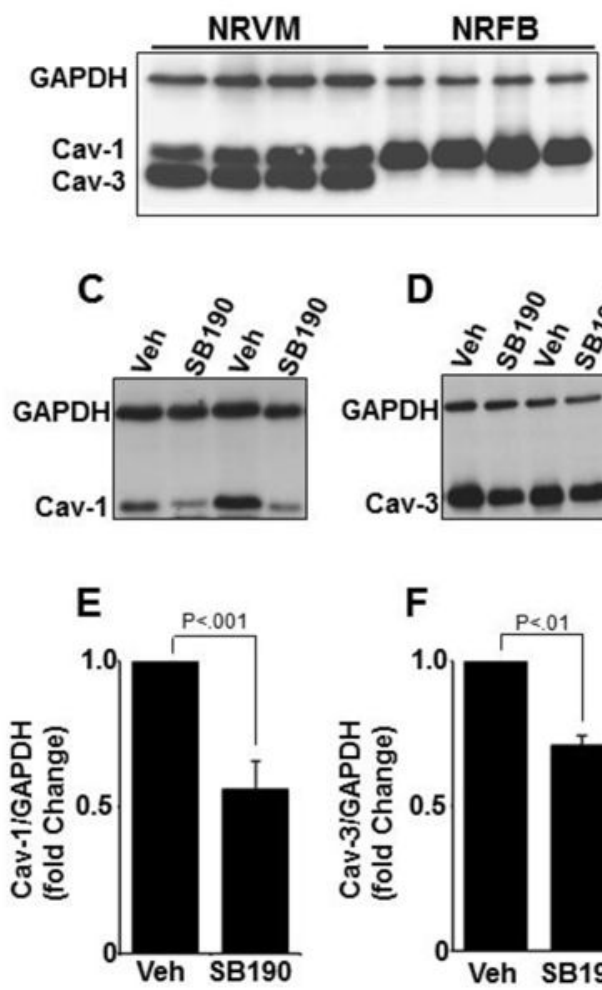

B
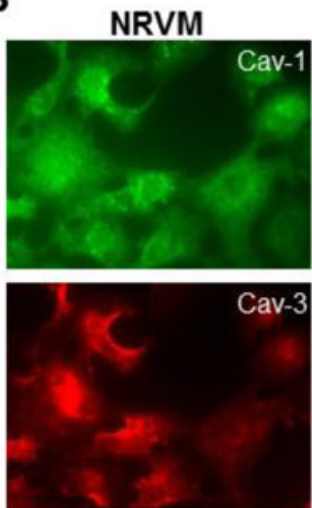

Cav-3
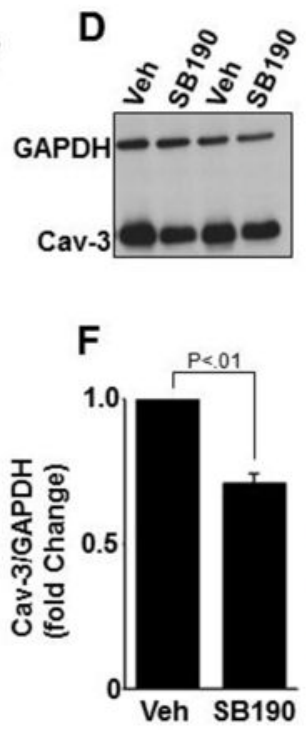
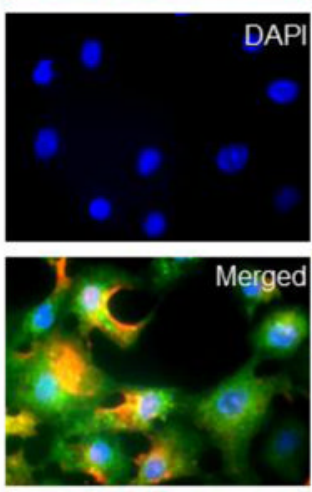

NRVM
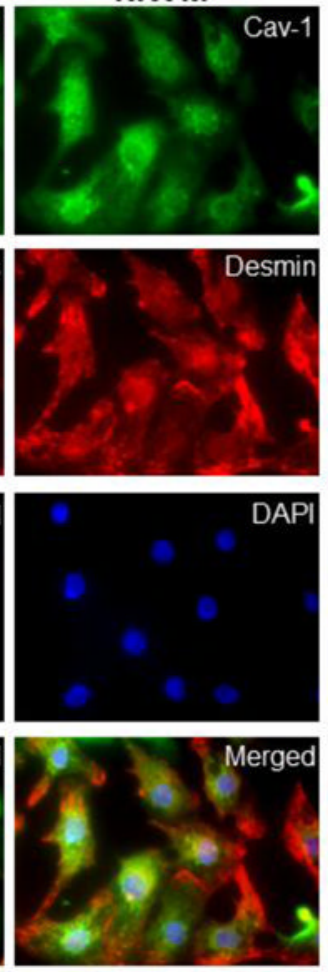

NRVM + NRFB
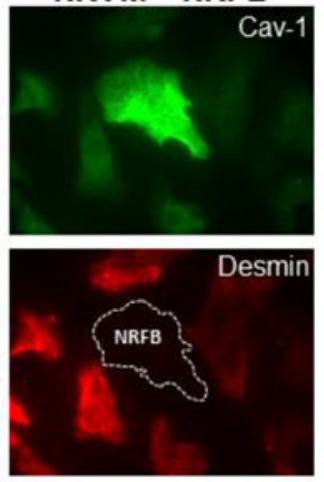

DAPI
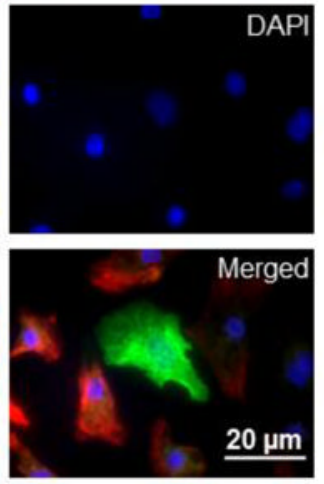

Figure 7. Cardiac myocytes express both Cav-1 and Cav-3 in a p38 dependent manner Western blot analysis of cell lysates and immunofluorescent staining demonstrates that NRVM express both Cav-1 and Cav-3 (A), whereas, neonatal rat cardiac fibroblasts (NRFB) express only Cav-1 (A and B). Immunofluorescent staining, using primary antibodies, demonstrate perinuclear staining for Cav-1, whereas Cav-3 was also localized along the cell borders (B). Western blots and immunofluorescent staining also indicate Cav-1 protein expression was higher in NRFB, compared to NRVM. When NRVM were treated for $24 \mathrm{~h}$ with a specific p38 inhibitor (10 $\mu \mathrm{M}$ SB202190), analysis of cell lysates by Western blot showed that inhibition of p38 cascade significantly decreased Cav-1 (C and E), as well as Cav-3 expression (D and F). However, treatment with inhibitors for ERK (10 $\mu$ M U0126), JNK1/2 (20 $\mu \mathrm{M}$ SP600125) had no effect on Cav-1 and Cav-3 protein expression (data not shown). N = 4 experiments. Veh, vehicle; SB190, SB20190; GAPDH, glyceraldehyde-3phosphate dehydrogenase; NRVM, neonatal rat ventricular myocytes; NRFB, neonatal rat ventricular fibroblasts. 


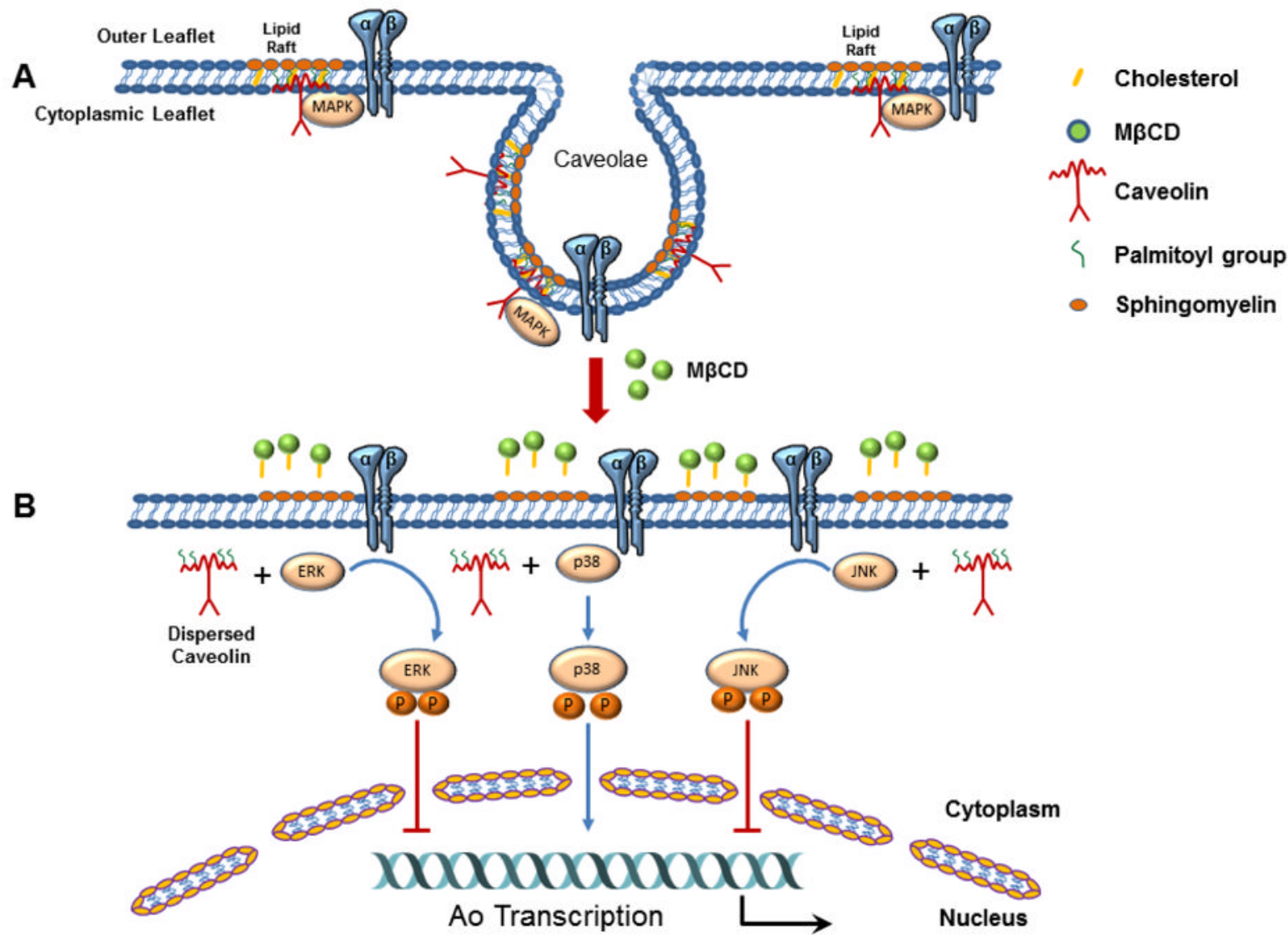

Figure 8. Model showing lipid raft/caveolae signaling and coupling to Ao gene expression in cardiac myocytes

Lipid rafts and caveolae are microdomains localized on the plasma membrane which known to integrate signaling pathways (A). Caveolae, or "little caves" are cholesterol and sphingolipid enriched invaginations of the plasma membrane. Results from this study suggest that caveolin-3 that is associated with caveolae stuctures, regulate MAPKs (ERK1/2, $\mathrm{p} 38$, JNK). Removal of cholesterol from the plasma membrane using M $\beta C D$, causes disruption of caveolae, as well as activation and release of MAPKs (B). Results from the present study indicate that activated forms of ERK1/2 and JNK serve as negative regulators of Ao gene expression, whereas p38 is a positive regulator. MBCD, methyl- $\beta$-cyclodextrin; MAPK, mitogen activated protein kinases. 